

\title{
Прогностическая значимость
} маркеров биохимического скрининга I триместра в оценке неблагоприятных факторов течения беременности у женщин, инфицированных
ВИЧ и гепатитами В и C

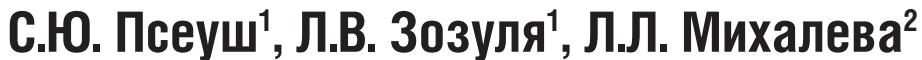

'ФГБОУ ВО «Кубанский государственный университет»; Россия, 350040 Краснодар, ул. Ставропольская, д. 149;

2П Перинатальный центр ГБУЗ «Детская краевая клиническая больница» Министерства здравоохранения Краснодарского края; Россия, 350007 Краснодар, площадь Победы, д. 1

Для контактов: Саида Юсуфровна Псеуш, e-mail: pseush-saida@mail.ru

Резюме

Цель исследования: выяснение прогностической значимости биохимических показателей сыворотки крови РАРР-А (англ. pregnancy-associated plasma protein A; ассоциированный с беременностью протеин А плазмы) и $\beta$-ХГЧ (бета-субъединица хорионического гонадотропина человека) в оценке неблагоприятных фракторов течения беременности у женщин с вирусом иммунодесицита человека (ВИЧ) и вирусными гепатитами В (ВГВ) и С (ВГС).

Материалы и методы. Проведено ретроспективное исследование историй болезни 52 женщин, среди которых было 19 ВИЧ-инфицированных, 9 моноинфицированных ВГВ или ВГС, 11 коинфицированных (ВИЧ/ВГВ или ВИЧ/ВГС), 13 неинфи-

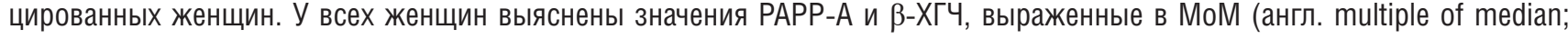
значение, кратное медиане).

Результаты. По итогам исследования выявлено, что прогностически значимыми для развития хронической фретоплацентарной недостаточности (ХФПН) у женщин с ВИЧ-инфекцией и ко-инфекцией ВИЧ и гепатитов В и С является только РАРР-А; у женщин с моноинфекцией ВГВ или ВГС ни один из исследованных маркеров не показал статистически значимого результата; у беременных без инфекций и РАРР-А и $\beta$-ХГЧ явились эффективными показателями в прогнозировании развития ХФПН.

Заключение: РАРР-А может быть использован в качестве диагностического маркера развития ХФПН у беременных с моноинфекцией ВИЧ и ко-инфекцией ВИЧ/ВГВ или ВИЧ/ВГС.

Ключевые слова: беременность, ВИЧ-инфекция, ко-инфекция, биохимический скрининг, ассоциированный с беременностью протеин А плазмы, РАРР-А, бета-субъединица хорионического гонадотропина человека, $\beta$-ХГЧ, хроническая фретоплацентарная недостаточность, синдром задержки развития плода

Для цитирования: Псеуш С.Ю., Зозуля Л.В., Михалева Л.Л. Прогностическая значимость маркеров биохимического скрининга I триместра в оценке неблагоприятных фракторов течения беременности у женщин, инфицированных ВИЧ и гепатитами В и С. Акушерство, Гинекология и Репродукция. 2021;15(6):686-694. https://doi.org/10.17749/2313-7347/ob.gyn. rep.2021.240.

\section{The predictive value indicators of first trimester biochemical screening in assessing unfavorable factors of pregnancy course in women with HIV as well as hepatitis B and C}

\author{
Saida Yu. Pseush', Lada V. Zozulya', Lada L. Mikhaleva²
}

${ }^{1}$ Kuban State University; 149 Stavropolskaya Str., Krasnodar 350040, Russia; 


\section{Perinatal Center «Children's Regional Clinical Hospital», Ministry of Health of Krasnodar Region; 1 Pobedy Square, Krasnodar 350007, Russia}

Corresponding author: Saida Yu.Pseush, e-mail: pseush-saida@mail.ru

\section{Abstract}

Aim: to find out the predictive value of blood serum biochemical parameters PAPP-A (pregnancy-associated plasma protein A) and $\beta$-hCG (beta subunit of human chorionic gonadotropin) in the assessment of unfavorable pregnancy outcomes in women infected by human immunodeficiency virus (HIV) as well as viral hepatitis B (HBV) and C (HCV).

Materials and Methods. A retrospective study of the medical records from 52 women was carried out, including 19 HIV-infected women, 9 women with monoinfection HBV or HCV, 11 pregnant women who were co-infected (HIV/HBV or HIV/HCV) and 13 uninfected women. PAPP-A and $\beta$-hCG levels, expressed as MoM (multiple of median), were evaluated in all women.

Results. Our study revealed that only PAPP-A was prognostically significant for developing chronic placental insufficiency in women with HIV infection and co-infection of HIV together hepatitis B and C. None of the parameters examined were significant in women with HBV or HCV monoinfection. PAPP-A and $\beta$-hCG in pregnant women without infections were effective in predicting development of chronic placental insufficiency.

Conclusion. PAPP-A can be used as a diagnostic parameter of developing chronic placental insufficiency in pregnant women with monoinfection HIV and co-infection with HIV/HBV or HIV/HCV.

Keywords: pregnancy, HIV-infection, co-infection, biochemical screening, pregnancy-associated plasma protein A, PAPP-A, beta subunit of human chorionic gonadotropin, $\beta$-hCG, chronic placental insufficiency, fetal growth retardation syndrome

For citation: Pseush S.Yu., Zozulya L.V., Mikhaleva L.L. The predictive value indicators of first trimester biochemical screening in assessing unfavorable factors of pregnancy course in women with HIV as well as hepatitis B and C. Akusherstvo, Ginekologia i Reprodukcia = Obstetrics, Gynecology and Reproduction. 2021;15(6):686-694. (In Russ.). https://doi.org/10.17749/2313-7347/ ob.gyn.rep.2021.240.

\section{Основные моменты}

\section{Что уже известно об этой теме?}

Биохимические маркеры сыворотки крови - РАРP-A (ассоциированный с беременностью протеин А плазмы) и

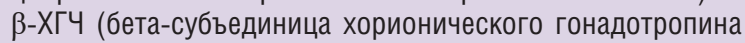
человека) могут быть использованы для прогноза неблагоприятных факторов течения и исходов беременности.

- При снижении РАРP-А до 0,5 МоМ (значение, кратное медиане) и менее и повышении $\beta$-ХГЧ до 2,00 МоМ риск развития патологий резко увеличивается.

- Беременные с ВИЧ-инфекцией и вирусными гепатитами В (ВГВ) и С (ВГС) часто характеризуются патологиями плаценты, вследствие чего у них развивается хроническая фетоплацентарная недостаточность и синдром задержки развития плода.

\section{Что нового дает статья?}

- Представлена сравнительная характеристика показателей биохимического скрининга I триместра беременности у инфицированных ВИЧ/ВГВ/ВГС и неинфицированных женщин.

- Прогностическая ценность РАРР-А у женщин с моноинфекцией ВИЧ и ко-инфекцией ВИЧ/ВГВ или ВИЧ/ВГС является высокой, в то время как $\beta$-ХГЧ не является статистически значимым маркером риска развития патологий беременности у инфицированных женщин.

Как это может повлиять на клиническую практику в обозримом будущем?

- При проведении пренатального скрининга у беременных с моноинфекцией ВИЧ и ко-инфекцией ВИЧ/ВГВ или ВИЧ/ВГС станет возможной оценка риска развития хронической фетоплацентарной недостаточности с помощью PAPP-A.

\section{Highlights}

What is already known about this subject?

Serum biochemical markers - PAPP-A (pregnancy-associated plasma protein $A$ ) and $\beta$-hCG (beta subunit of human chorionic gonadotropin) can be used for predicting unfavorable factors in the course and outcomes of pregnancy.

Upon decrease in PAPP-A to 0.5 MoM (multiple of median) or lower and increase in $\beta$-hCG up to 2.00 MoM, the risk of developing pathologies increases sharply.

- Pregnant women with HIV-infection as well as hepatitis B (HBV) and $\mathrm{C}(\mathrm{HCV})$ virus are often characterized by pathologies of the placenta, thereby resulting in developed chronic placental insufficiency and fetal growth retardation syndrome.

\section{What are the new findings?}

- Comparative characteristics of biochemical screening indicators for the first trimester of pregnancy in HIV/HBV/HCV infected and uninfected women are presented.

PAPP-A in women with HIV monoinfection and co-infection with HIV/HBV or HIV/HCV has a high predictive value, whereas $\beta$-hCG is not a significant risk marker for developing pregnancy pathologies infected women.

How might it impact on clinical practice in the foreseeable future?

- While conducting a prenatal screening in women with HIV monoinfection as well as co-infection with HIV/HBV or $\mathrm{HIV/HCV}$, it would make possible to assess a risk of emerging chronic fetal growth retardation syndrome by measuring PAPP-A. 


\section{Введение / Introduction}

Инфицирование женщин репродуктивного возраста ВИЧ-инфекцией и гепатитами В (ВГВ) и С (ВГС) в настоящее время остается актуальной проблемой. Так, по данным В03, количество ВИЧ-инсрицированных в мире на 2019 г. составило 38 млн человек, из которых 48 \% приходится на женское население [1]. На территории Российской Федерации общее количество инфицированных составило 1426976 человек, а количество ВИЧ-инсрицированных беременных превысило 1 \% от общего количества беременных женщин [2], что свидетельствует о генерализации процесса инфицирования.

Известно, что одними из наиболее распространенных ко-инфекций вируса иммунодесрицита человека (ВИЧ) являются вирусные гепатиты В и С, маркеры которых выявляются у ВИЧ-инфрицированных в 70 и $40 \%$ соответственно [3, 4].

Совместное течение исследуемых иноекций у беременных часто сопровождается патологиями беременности, среди которых отмечаются маловодие, многоводие, преждевременный разрыв плодных оболочек. Однако наиболее важными патологиями, оказывающими влияние на течение и исход беременности, являются хроническая фетоплацентарная недостаточность (ХФПН) и вызванный ею синдром задержки внутриутробного развития плода (СЗРП) [5]. Поэтому особый интерес представляет возможность прогнозирования подобных нарушений беременности, для чего могут быть использованы маркеры биохимического скрининга I триместра в виде ассоциированного с беременностью плазменного белка А (англ. pregnancyassociated plasma protein A, PAPP-A) и свободной субъединицы хорионического гонадотропина человека ( $\beta$ ХГЧ). Данные биохимические показатели наряду с ультразвуковым исследованием входят в обязательный пренатальный скрининг I триместра беременности (11-13 нед), а изменения маркеров свидетельствуют о хромосомных аномалиях развивающегося плода. В связи с тем, что РАРР-А и $\beta$-ХГЧ вырабатываются в организме по большей части плацентой, исследователями изучается вопрос о влиянии изменения концентрации маркеров на неблагоприятные фракторы течения и исхода беременности, в том числе преэклампсию, преждевременные роды, СЗРП и др. По итогам исследований, некоторыми авторами отмечается корреля-

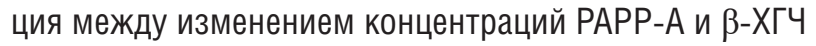
и неблагоприятными исходами; при этом наибольшая чувствительность и специфичность наблюдается при снижении РАРP-A менее 0,5 МоМ (англ. multiple of median; значение, кратное медиане) и повышении $\beta$-ХГЧ свыше 2,00 МоМ [6]. Однако многими авторами подобная взаимосвязь не выявляется, а исследований изменения данных биохимических маркеров у женщин с ВИЧ и гепатитами В и С крайне мало.
Цель исследования: выяснение прогностической значимости биохимических показателей сыворотки крови РАРР-А и $\beta$-ХГЧ в оценке неблагоприятных факторов течения беременности у женщин с ВИЧ и вирусными гепатитами В и C.

\section{Материалы и методы / Materials and Methods}

\section{Дизайн исследования / Study design}

В ходе исследования было проведено ретроспективное изучение историй болезни 52 беременных в возрасте от 21 до 41 года, наблюдавшихся в ГБУЗ PA «Майкопская городская клиническая больница» и в Перинатальном центре ГБУЗ «Детская краевая клиническая больница» МЗ КK (Краснодар).

Беременные были распределены по группам в зависимости от инсеекционного статуса (рис. 1): в основную группу (группа 1) вошли 39 инфицированных женщин, в контрольную группу (группа 2) - 13 неинсиицированных. Группа 1 в зависимости вида инфекции была разделена на 3 подгруппы: группу $1 \mathrm{~A}$ составили женщины с ВГВ или ВГС $(n=9)$, группу $1 \mathrm{~B}$ - женщины, инсицированные ВИЧ $(n=19)$, группу $1 \mathrm{C}$ - беременные, ко-инсрицированные ВИЧ/ВГВ или ВИЧ/ВГС $(n=11)$.

\section{Критерии включения и исключения / Inclusion and exclusion criteria}

Критерии включения в основную группу: наличие моно- и ко-инсекции ВИЧ и гепатитов В и С; прохождение биохимического скрининга I триместра беременности с исследованием РАРP-А и $\beta$-ХГЧ; наличие в медицинских картах документированных сведений об особенностях течения беременности.

Критерии включения в контрольную группу: отсутствие ВИЧ-инсекции и вирусных гепатитов В и C в анамнезе, а также других инсекций, передаваемых

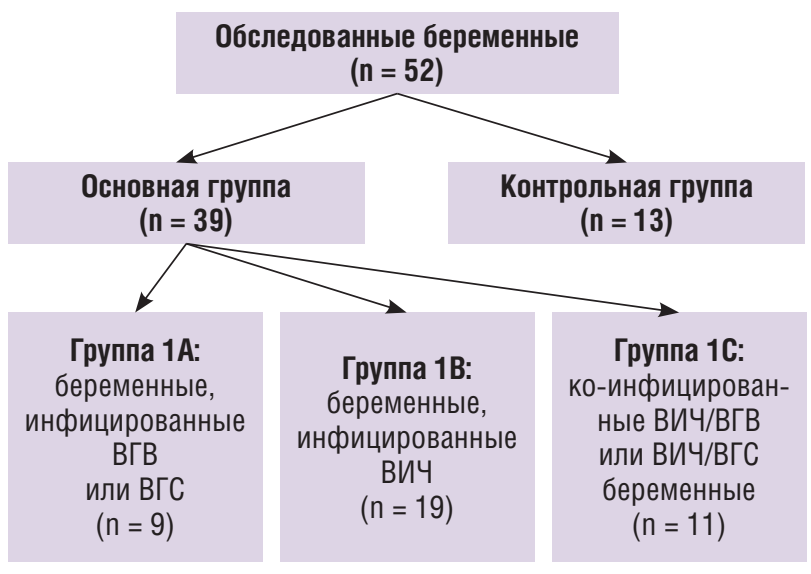

Рисунок 1. Дизайн исследования.

Figure 1. Study design. 
половым путем, способных оказать влияние на течение и исход беременности; прохождение биохимического скрининга I триместра беременности с исследованием РАРР-А и $\beta$-ХГЧ; наличие в медицинских картах документированных сведений об особенностях течения беременности.

Критерии исключения: наличие хромосомных аномалий плода; прерывание беременности по медицинским показаниям.

\section{Методы обследования / Study methods}

У всех женщин в сыворотке крови были определены маркеры биохимического скрининга I триместра беременности (РАРР-А, МоМ; $\beta$-ХГЧ, МоМ), выяснены осложнения течения беременности.

Взятие крови производили натощак из локтевой вены в объеме 15-20 мл. Пробоподготовку осуществляли путем центрифугирования в течение 15 мин при ускорении 3000 g. Определение РАРР-А проводили с помощью автоматического биохимического анали-

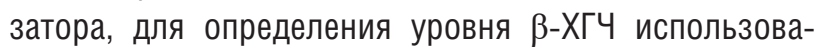
ли Architect i2000 (Abbott Diagnostics, США), в основе работы которых лежит иммунохемилюменисцентный анализ. Принцип определения рассматриваемых показателей заключается в образовании иммунного комплекса «антиген-антитело», меченного флуоресцентной меткой. Полученные в результате анализа значения выражаются в МЕ/л. Однако в связи с тем, что РАРР-А и $\beta$-ХГЧ являются компонентами пренатального скрининга I триместра беременности, впоследствии производится автоматический пересчет результатов в МоМ для прогнозирования риска развития хромосомных аномалий плода. Расчет конечных показателей (РАРР-А, МоМ и $\beta$-ХГЧ, МоМ) производили с помощью программы Life Cycle.

\section{Этические аспекты / Ethical aspects}

Исследование проведено в соответствии с Хельсинкской декларацией Всемирной медицинской ассо- циации (пересмотр 2013 г., Форталеза, Бразилия), правилами Надлежащей клинической практики и другими применяемыми в Российской Федерации нормативными документами. Все обследованные женщины подписывали инорормированное добровольное согласие.

\section{Статистический анализ / Statistical analysis}

Статистический анализ проводили с помощью программы IBM SPSS Statistics (IBM, США). Все полученные данные охарактеризованы с помощью медианы (Ме) с интерквартильным размахом $\left(Q_{25}-Q_{75}\right)$, так как большинство из них распределены ненормально (тест Колмогорова-Смирнова). Сравнение средних тенденций производили с помощью однофакторного дисперсионного анализа (критерий Краскела-Уоллиса) при уровне значимости $p \leq 0,05$. Для расчета прогностической значимости исследуемых показателей использовали ROC-кривые с указанием 95 \% доверительного интервала (95 \% ДИ). Статистически значимым результат считали при значении площади под кривой более 0,5 (AUC > 0,5).

\section{Результаты и обсуждение/ Results and Discussion}

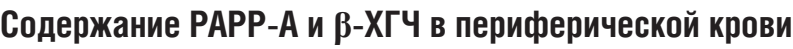 и ассоциированные с ними неблагоприятные факторы течения беременности у обследованных женщин / Level of peripheral blood PAPP-A and $\beta$-hCG and their associated adverse factors of pregnancy in women studied}

В ходе исследования нами были получены средние значения показателей биохимического скрининга во всех изучаемых группах (табл. 1).

Наиболее низкими значениями РАРР-А характеризовалась группа без инфекционной патологии (контрольная группа), в то время как самые высокие показатели $\beta$-ХГЧ отмечались в группе ко-инфицирован-

Таблица 1. Результаты биохимического скрининга.

Table 1. Biochemical screening results.

\begin{tabular}{|c|c|c|}
\hline $\begin{array}{l}\text { Группа беременных } \\
\text { Pregnant group }\end{array}$ & $\begin{array}{l}\text { PAPP-A, MoM } \\
\text { Me }\left(Q_{25}-Q_{75}\right)\end{array}$ & 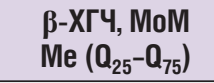 \\
\hline $\begin{array}{l}\text { C моноинфекцией ВГВ или ВГС (группа } 1 \text { A; } n=9 \text { ) } \\
\text { With HBV or HCV monoinfection (group } 1 A ; n=9)\end{array}$ & $1,17(0,75-1,88)$ & $0,96(0,54-1,69)$ \\
\hline $\begin{array}{l}\text { C моноинсрекцией ВИЧ (группа 1B; } n=19 \text { ) } \\
\text { With HIV monoinfection (group 1A; } n=19 \text { ) }\end{array}$ & $1,13(0,75-1,33)$ & $0,79(0,59-1,29)$ \\
\hline $\begin{array}{l}\text { Ко-инсрицированные ВИЧ/ВГВ или ВИЧ/ВГС (группа 1C; } \mathrm{n}=11 \text { ) } \\
\text { HIV/HBV or HIV/HCV co-infection (group 1C; } \mathrm{n}=11 \text { ) }\end{array}$ & $1,22(0,65-1,44)$ & $1,32(0,70-1,57)$ \\
\hline $\begin{array}{l}\text { Hеинсрицированные (контрольная группа; } n=13 \text { ) } \\
\text { Uninfected (control group; } n=13 \text { ) }\end{array}$ & $0,94(0,43-1,23)$ & $0,75(0,63-1,45)$ \\
\hline
\end{tabular}

Примечание: ВГВ - гепатит В; ВГС - гепатит С; ВИЧ - вирус иммунодефицита человека; РАРР-А - ассоциированный с беременностью плазменный

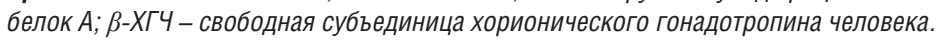

Note: HBV - hepatitis B virus; HCV - hepatitis C virus; HIV - human immunodeficiency virus; PAPP-A - pregnancy-associated plasma protein A; $\beta$-hCG - free subunit of human chorionic gonadotropin. 
ных беременных (группа 1C). Однако значимых различий между группами выявлено не было ( $p \geq 0,05)$.

В связи с тем, что рассматриваемые показатели биохимического скрининга являются соединениями, продуцируемыми цитотрофобластом, они могут выступать в качестве диагностических маркеров состояния плода и свидетельствовать о патологиях его развития. СЗРП, являясь важным осложнением беременности ВИЧ-инфицированных женщин, зачастую связан с нарушением трофической функции плаценты, проявляющейся в хронической фетоплацентарной недостаточности. По результатам нашего исследования, у беременных, инфицированных ВИЧ и ко-инфицированных ВИЧ и гепатитами В и С, течение беременности характеризовалось высоким риском развития ХФПН и СЗРП по сравнению с другими группами. Так, у женщин 1В группы ХФПН диагностировалась в 36,8 \% случаев, из которых СЗРП развивался у 28,5 \% беременных. Среди инсрицированных 1С группы данные значения составляли $63,6 \%$ и 42,8 \% соответственно. В остальных группах выявляемость ХФПН и СЗРП была существенно ниже: в группе 1 А - 37,5 \% и 0 \%, в группе 2 - 23,1\% и 0,0\%.

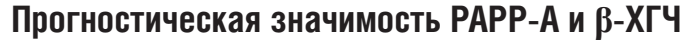 в развитии хронической фетоплацентарной недостаточности и синдрома задержки развития плода / Prognostic significance of PAPP-A and $\beta$-hCG in development of chronic placental insufficiency and fetal growth retardation syndrome}

При сопоставлении результатов биохимического скрининга и развития патологий беременности, сопровождавших период гестации у инфицированных женщин, нами было установлено, что ко-инсиццированные беременные, у которых отмечалась наиболее высокая выявляемость ХФПН и СЗРП, также имели более высокие показатели РАРР-А и $\beta$-ХГЧ. При этом у 3 женщин в группе 1C показатели РАРР-А принимали крайние значения, близкие к 0,5 MoМ (2 женщи-

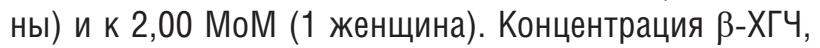
превышающая 2,00 МоM, не наблюдалась ни у одной беременной. Мнения авторов относительно чувствительности и специфичности маркеров биохимического скрининга в прогнозировании исследуемых патологий беременности неоднозначны. Так, Т.А. Заманская с соавт. (2009) не обнаруживали изменений

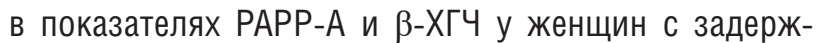
кой внутриутробного развития плода по сравнению с беременными без патологий [7]. В то же время Е.В. Кудрявцева с соавт. (2020) выявили достоверные отличия биохимических показателей у женщин с неблагоприятным течением и исходом беременности по сравнению с контрольной группой [8]. Кроме того, многими авторами отмечается высокий уровень специфричности снижения концентрации РАРР-А в период I триместра гестации к развитию СЗРП, а разнона- правленные изменения концентраций РАРР-А и $\beta$-ХГЧ являются наиболее неблагоприятными сракторами прогноза [9-11].

По результатам нашего исследования было выявлено, что в группах ВИЧ-инфицированных и ко-инфицированных беременных снижение концентрации РАРР-А позволяло эффрективно прогнозировать раз-

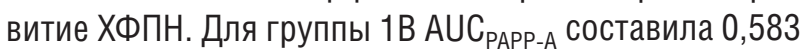
(95\% ДИ =0,31-0,86), а для 1С - 0,79 (95\% ДИ = 0,49-1,00) (рис. 2). Однако при оценке эффективности прогностической значимости повышения концентрации $\beta$-ХГЧ соотношение чувствительности и специфичности оказалось незначимым.

При изучении соотношения специсичности и чувствительности биохимических маркеров у беременных, инфицированных гепатитами В и С, было выявлено, что ни один из исследованных биохимических маркеров не является прогностически значимым для ХФПН: $A_{\text {PAРP-A }}=0,389$ (95\% ДИ =0,0-0,90),

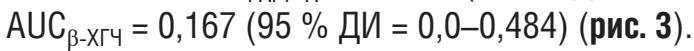

При сравнении прогностической ценности биохимических маркеров у неинфицированных женщин было выявлено, что в отличие от всех инфицированных беременных, оба показателя (снижение концентрации РАРР-А и повышение концентрации $\beta$-ХГЧ) у данной группы обладает статистически значимой прогностической ценностью при AUC $_{\text {PAPР-А }}=0,67$

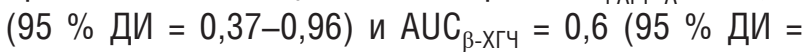
0,21-0,99) (рис. 4).

Таким образом, по нашим данным, прогностически важным для инфицированных ВИЧ и ко-инфицированных женщин (группы 1В и 1С) является лишь показатель РАРР-А, для беременных без инфекционной патологии (контрольная группа) высокую диагностическую значимость имеют оба биохимических маркера, в то время как для инфицированных гепатитами В и C (группа 1А) ни один из исследованных показателей не обладает прогностической ценностью.

Высокая прогностическая значимость рассматриваемых биохимических показателей среди неинфицированных беременных подтверждается исследованиями В.И. Цибизовой с соавт. (2020), обнаружившими корреляцию снижения РАРP-А ниже 0,5 МоМ с неблагоприятными исходами беременности и особенно с антенатальной гибелью плода [12]. Наблюдаемые в нашем исследовании расхождения в прогностической значимости биохимических маркеров у инфицированных женщин могут быть связаны с особенностями патогенеза исследуемых инфекций и их специфическим воздействием на развивающуюся плаценту [13-15]. Так, согласно А.В. Колобову (2015), вирус способствует дегенеративным процессам синцитиокапиллярной мембраны, приводя к повреждению ткани по плацентарно-мембранному механизму [16]. Об этом свидетельствует изменение экспрессии гена FasL, являющегося специфическим для синцитиотрофобласта. 

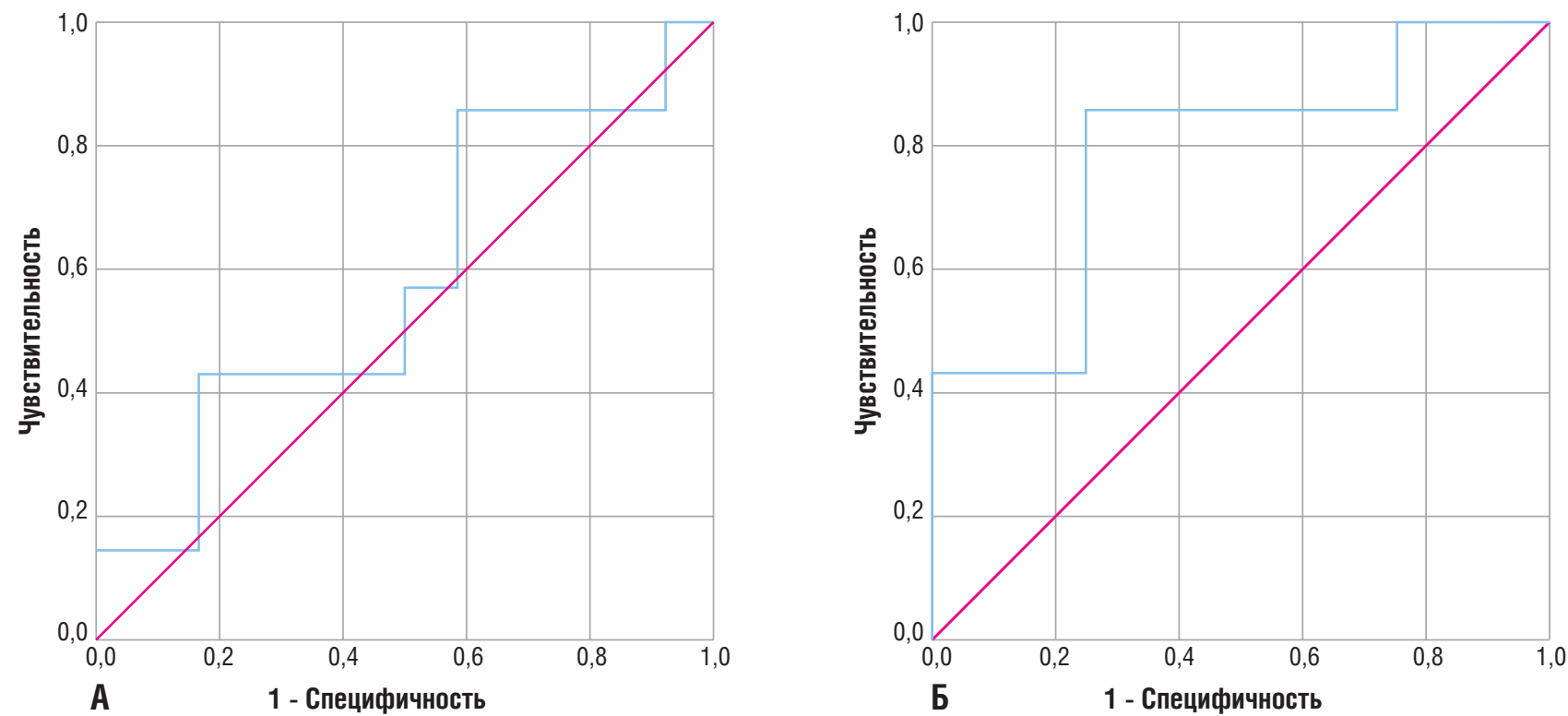

Рисунок 2. ROC-кривые по показателю РАРP-А для прогнозирования хронической фретоплацентарной недостаточности у беременных, моноинфицированных ВИЧ (А, группа 1В) и ко-инсрицированных (Б, группа 1 C): AUC $_{\text {PAPP-A }}=0,583(95 \%$ ДИ = 0,31-0,86);

$A \cup C_{\text {PAPP-A }}=0,79(95 \%$ ДИ $=0,49-1,00)$.

Figure 2. ROC-curves for PAPP-A to predict chronic placental insufficiency in pregnant women with HIV monoinfection (A, group 1B) or coinfection (Б, group 1C): $A \cup C_{\text {PAPP-A }}=0.583$ (95\% ДИ =0.31-0.86); AUC $_{\text {PAPP-A }}=0.79$ (95\% ДИ =0.49-1.00).
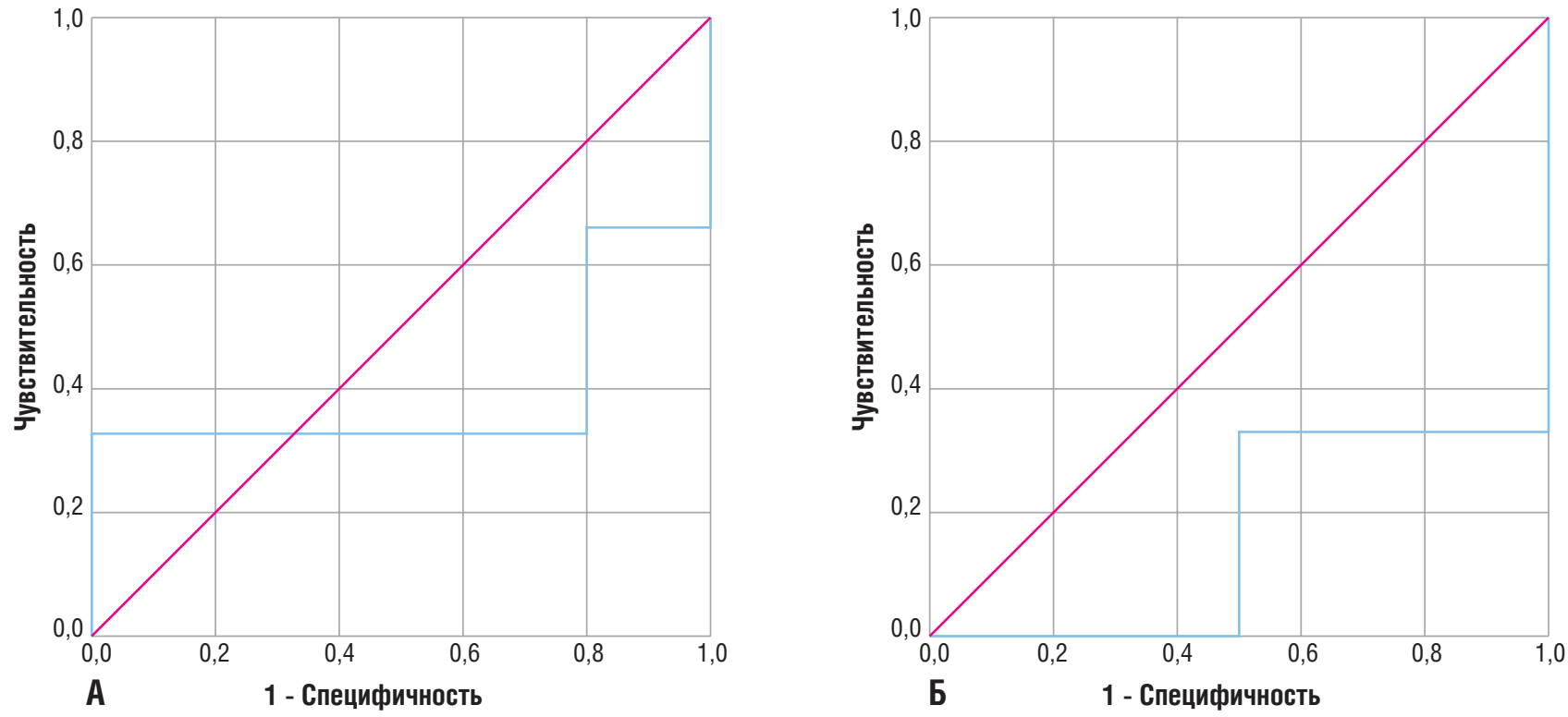

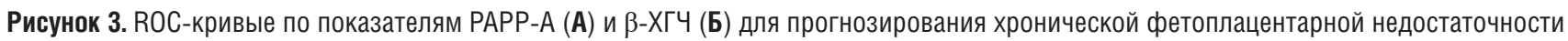
у моноинфицированных ВГВ или ВГС беременных (группа 1A): AUC $_{\text {PAPP-A }}=0,389(95 \%$ ДИ =0,0-0,90);

$\mathrm{AUC}_{\beta-\mathrm{X} Г}=0,167(95 \%$ ДИ = 0,0-0,484).

Figure 3. ROC-curves for PAPP-A (A) and $\beta$-hCG (Б) to predict chronic placental insufficiency in pregnant women with HBV or HCV

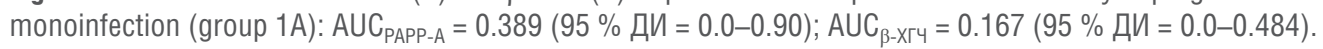

В связи с тем, что за синтез свободной $\beta$-субъединицы хорионического гонадотропина человека отвечают клетки синцитиотрофробласта, процессы секреции при инфицировании могут нарушаться, вследствие чего и происходит снижение прогностической значимости маркера.
Отсутствие эффективности прогнозирования у беременных с моноинфекцией ВГВ или ВГС может также быть следствием особенностей поражения фетоплацентарного комплекса. В данном случае, кроме изменений в синцитиокапиллярной мембране, отмечается снижение продукции некоторых гормонов 

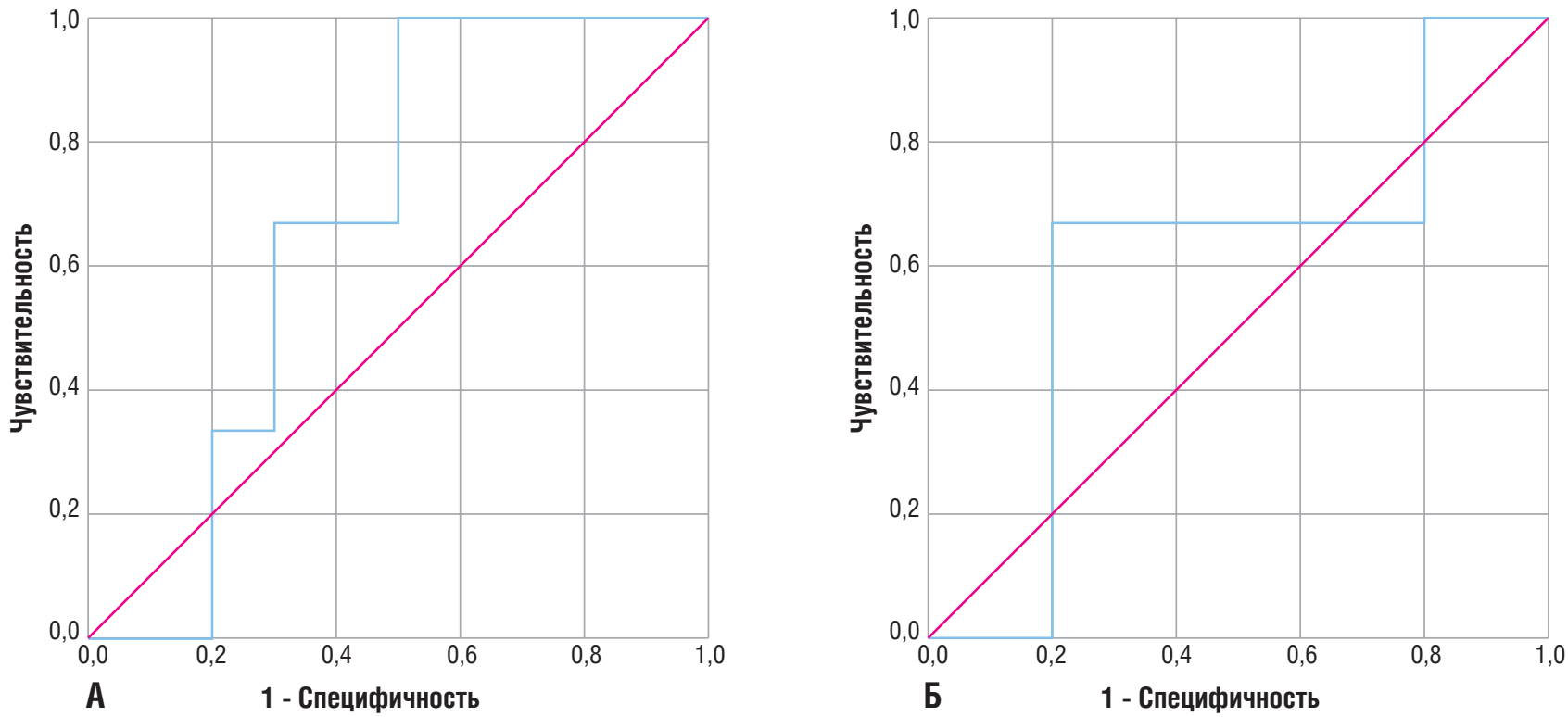

Рисунок 3. ROC-кривые по показателям РAPP-A (А) и $\beta$-ХГЧ (Б) для прогнозирования хронической фетоплацентарной недостаточности у неинсрицированных беременных (контрольная группа): $\mathrm{AUC}_{\text {PAPP-A }}=0,67$ (95\% ДИ = 0,37-0,96); $A \cup \mathrm{C}_{\beta-\text { хгч }}=0,6(95 \%$ ДИ = 0,21-0,99).

Figure 3. ROC-curves for PAPP-A (A) and $\beta$-hCG (E) to predict chronic placental insufficiency in uninfected pregnant women (control group):

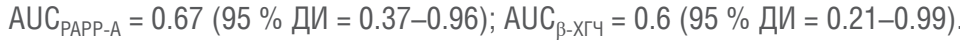

и воспаление децидуальной оболочки, продуцирующей РАРР-A [17].

\section{Заключение / Conclusion}

Таким образом, беременные женщины, инфицированные ВИЧ и вирусными гепатитами В и С, отличаются высоким риском развития патологий беременности в виде ХФПН и СЗРП по сравнению с неинсрицирован- ными женщинами. Прогнозирование развития данных патологий у обследованных беременных также имеет свои особенности: для беременных с ВИЧ-инфекцией и ко-инфицированных женщин эфффективным фрактором прогноза является только снижение концентрации РАРP-А, а для беременных с моноинфекцией ВГВ или ВГС, по нашим данным, ни один из рассмотренных маркеров не может быть использован в качестве прогностически важного.

\begin{tabular}{|c|c|}
\hline ИНФОРМАЦИЯ О СТАТЬЕ & ARTICLE INFORMATION \\
\hline Поступила: 23.07.2021. В доработанном виде: 23.08.2021. & Received: 23.07.2021. Revision received: 23.08.2021. \\
\hline Принята к печати: 17.09.2021. Опубликована: 30.12.2021. & Accepted: 17.09.2021. Published: 30.12.2021. \\
\hline Вклад авторов & Author's contribution \\
\hline $\begin{array}{l}\text { Все авторы принимали равное участие в сборе, анализе и интерпретации } \\
\text { данных. }\end{array}$ & $\begin{array}{l}\text { All authors participated equally in the collection, analysis and interpretation } \\
\text { of the data. }\end{array}$ \\
\hline Все авторы прочитали и утвердили окончательный вариант рукописи. & All authors have read and approved the final version of the manuscript. \\
\hline Конфликт интересов & Conflict of interests \\
\hline Авторы заявляют об отсутствии конфрликта интересов. & The authors declare no conflict of interest. \\
\hline Финансирование & Funding \\
\hline $\begin{array}{l}\text { Авторы заявляют об отсутствии необходимости раскрытия фиинансо- } \\
\text { вой поддержки. }\end{array}$ & The authors declare they have nothing to disclose regarding the funding. \\
\hline Согласие пациентов & Patient consent \\
\hline Получено. & Obtained. \\
\hline Политика раскрытия данных & Clinical Trials Disclosure Policy \\
\hline $\begin{array}{l}\text { Первичные данные могут быть предоставлены по обоснованному } \\
\text { запросу автору, отвечающему за корреспонденцию. Предложения } \\
\text { следует направлять на почтовый ящик pseush-saida@mail.ru. }\end{array}$ & $\begin{array}{l}\text { Raw data could be provided upon reasonable request to the corresponding } \\
\text { author. Proposals should be directed to pseush-saida@mail.ru. }\end{array}$ \\
\hline Происхождение статьи и рецензирование & Provenance and peer review \\
\hline Журнал не заказывал статью; внешнее рецензирование. & Not commissioned; externally peer reviewed. \\
\hline
\end{tabular}




\section{Литература:}

1. HIV/AIDS. World Health Organization, 2021. Available at: https://www. who.int/news-room/fact-sheets/detail/hiv-aids. [Accessed: 15.07.2021].

2. Ладная Н.Н., Покровский В.В., Дементьева Л.А., Соколова Е.В. Эпидемическая ситуация по ВИЧ-инфекции в Российской Федерации в 2019 г. Эпидемиология и инфекционные болезни. Актуальные вопросы. 2020;10(3):17-26.

3. Гепатит С и ВИЧ-инфекция: тактика ведения пациентов с сочетанной инфекцией. Клинический протокол для Европейского региона В0З. Всемирная организация здравоохранения, 2006. 53 с. Режим доступа: https://www.euro.who.int/_data/assets/pdf_file/0010/78148/HEP_C_rus. pdf. [Дата доступа: 15.07.2021].

4. Гепатит В и ВИЧ-инфекция: тактика ведения пациентов с сочетанной инфекцией. Клинический протокол для Европейского региона В03. Всемирная организация здравоохранения, 2006. 31 с. Режим доступа: https://www.euro.who.int/_data/assets/pdf_file/0007/91942/HEP_B_rus. pdf. [Дата доступа: 15.07.2021].

5. Богомолова И.В. Некоторые аспекты хронической фетоплацентарной дисфункции и перинатальные исходы у ВИЧ-инфицированных беременных. Журнал акушерства и женских болезней. 2017;66(S):102-3.

6. Mohamad J.R., Masihi S., Barati M. et al. Value of pregnancy-associated plasma protein-A for predicting adverse pregnancy outcome. Arch Iran Med. 2019;22(10):584-7. PMID: 31679360.

7. Заманская Т.А., Евсеева З.П., Евсеев А.В. Биохимический скрининг В I триместре при прогнозировании осложнений беременности. Российский вестник акушера-гинеколога. 2008;8(3):71-3.

8. Кудрявцева Е.В., Ковалев В.В., Баранов И.И. и др. Взаимосвязь показателей пренатального скрининга I триместра с риском осложнений беременности. Акушерство и гинекология. Новости. Мнения. Обучение. 2020;8(1):38-46. https://doi.org/10.24411/2303-9698-2020-11005.

9. Каспарова А.Э., Белоцерковцева Л.Д., Коваленко Л.В., Сус Л.А. Скрининги в ранние сроки беременности: возможен ли прогноз формирования кардиоплацентарной недостаточности при преэклампсии. Вестник РуДН. Серия: Медицина. 2011;(S5):123-32.

\section{References:}

1. HIV/AIDS. World Health Organization, 2021. Available at: https://www. who.int/news-room/fact-sheets/detail/hiv-aids. [Accessed: 15.07.2021].

2. Ladnaya N.N., Pokrovsky V.V., Dementyeva L.A., Sokolova E.V. The epidemic situation of HIV infection in the Russian Federation in 2019 [Epidemicheskaya situaciya po VICh-infekcii v Rossijskoj Federacii v 2019 g]. Epidemiologiya i infekcionnye bolezni. Aktual'nye voprosy. 2020;10(3):17-26. (In Russ.).

3. Hepatitis $\mathrm{C}$ and HIV infection: management tactics for patients with co-infection. Clinical protocol for the WHO European Region. [Gepatit S i VICh-infekciya: taktika vedeniya pacientov s sochetannoj infekciej. Klinicheskij protokol dlya Evropejskogo regiona V0Z]. Vsemirnaya organizaciya zdravoohraneniya, 2006. 53 p. (In Russ.). Available at: https://www.euro.who.int/_data/assets/pdf_file/0010/78148/HEP_C_rus pdf. [Accessed: 15.07.2021].

4. Hepatitis B and HIV infection: management tactics for patients with co-infection. Clinical protocol for the WHO European Region. [Gepatit B i VICh-infekciya: taktika vedeniya pacientov s sochetannoj infekciej. Klinicheskij protokol dlya Evropejskogo regiona VOZ]. Vsemirnaya organizaciya zdravoohraneniya, 2006. 31 p. (In Russ.). Available at: https://www.euro.who.int/_data/assets/pdf_file/0007/91942/HEP_B_rus. pdf. [Accessed: 15.07.2021].

5. Bogomolova I.V. Some aspects of chronic placental dysfunction and perinatal outcomes in HIV-infected pregnant women. [Nekotorye aspekty hronicheskoj fetoplacentarnoj disfunkcii i perinatal'nye iskhody u VIChinficirovannyh beremennyh]. Zhurnal akusherstva i zhenskih boleznej. 2017;66(S):102-3. (In Russ.).

6. Mohamad J.R., Masihi S., Barati M. et al. Value of pregnancy-associated plasma protein-A for predicting adverse pregnancy outcome. Arch Iran Med. 2019;22(10):584-7. PMID: 31679360.

7. Zamanskaya T.A., Evseeva Z.P., Evseev A.V. Biochemical screening in the first trimester on predicting the complications of pregnancy. [Biohimicheskij skrining v I trimestre pri prognozirovanii oslozhnenij
10. Кыстаубаева А.С., Танышева Г.А., Шарипова М.Г. и др. Влияние уровня содержания ассоциированного с беременностью плазменного белка-А (РАРР-А) на развитие нарушений роста плода. Наука и здравоохранение. 2017;(5):55-66.

11. Николаева Ю.А, Кащеева Т.К., Баранов В.С. Значение маркерных сывороточных белков для прогноза патологии течения беременности и состояния новорожденного. Журнал акушерства и женских болезней. 2012;61(3):94-103.

12. Цибизова В.И., Говоров И.Е., Первунина Т.М. и др. Пренатальный скрининг первого триместра при многоплодной беременности. Часть II: сывороточные белки РАРР-А и $\beta$-ХГЧ как маркеры неблагоприятных исходов беременности. Акушерство, Гинекология и Репродукция. 2020;14(1):34-43. https://doi.org/10.17749/23137347.2020.14.1.34-43.

13. Obimbo M.M., Zhou Y., McMaster M.T. et al. Placental structure in preterm birth among HIV-positive versus HIV-negative women in Kenya. J Acquir Immune Defic Syndr. 2019;80(1):94-102. https://doi.org/10.1097/QAI.0000000000001871.

14. Тусупбекова М.М., Кизатова С.Т. Особенности патоморфологии у детей при перинатальной ВИЧ-инфекции и поражения плаценты при ВИч/СПИДе у женщин. Теоретическая и экспериментальная медицина. 2017;(4):86-93.

15. Белоцерковцева Л.Д., Коваленко Л.В., Тефнанц Н.А., Каспарова А.Э. Морфофункциональные изменения в плаценте у пациенток с ВИЧ при вирусном поражении детей инфекцией. Вестник Новгородского государственного университета. 2018;(6):4-8.

16. Колобов А.В. Морфогенез плаценты человека и ее морфофункциональное состояние при патологии беременности. Вестник Санкт-Петербургского университета. 2015;11(2):5-18.

17. Курбанов Ш.М., Рахматуллоева Д.М., Юлдашева 0.Э., Багдасарова H.X. Особенности фетоплацентарного комплекса у беременных с вирусными гепатитами. Вестник Авиценны. $2011 ;(2): 44-8$.

beremennosti]. Rossijskij vestnik akushera-ginekologa. 2008;8(3):71-3. (In Russ.).

8. Kudryavtseva E.V., Kovalev V.V., Baranov I.I. et al. Correlation of prenatal screening indicators of the I trimester with the risk of pregnancy complications. [Vzaimosvyaz' pokazatelej prenatal'nogo skrininga I trimestra s riskom oslozhnenij beremennosti]. Akusherstvo i ginekologiya. Novosti. Mneniya. Obuchenie. 2020;8(1):38-46. (In Russ.). https://doi.org/10.24411/2303-9698-2020-11005.

9. Kasparova A.E., Belotserkovtseva L.D., Kovalenko L.V., Sus L.A. Screenings in early pregnancy: is it possible to predict the formation of cardio-placental insufficiency in preeclampsia. [Skriningi v rannie sroki beremennosti: vozmozhen li prognoz formirovaniya kardio-placentarnoj nedostatochnosti pri preeklampsii]. Vestnik RUDN. Seriya: Medicina. 2011;(S5):123-32. (In Russ.).

10. Kystaubayeva A.S., Tanysheva G.A., Sharipova M.G. et al. The influence of pregnancy-associated plasma proteinA (PAPP-A) on intrauterine growth restriction. [Vliyanie urovnya soderzhaniya associirovannogo s beremennost'yu plazmennogo belka-A (RARR-A) na razvitie narushenij rosta ploda]. Nauka i zdravoohranenie. 2017;(5):55-66. (In Russ.).

11. Nikolaeva Yu.A., Kascheeva T.K., Baranov V.S. The role of biochemical maternal serum markers in prognosis of obstetrical complications. [Znachenie markernyh syvorotochnyh belkov dlya prognoza patologii techeniya beremennosti i sostoyaniya novorozhdennogo]. Zhurnal akusherstva i zhenskih boleznej. 2012;61(3):94-103. (In Russ.).

12. Tsibizova V.I., Govorov I.E., Pervunina T.M. et al. First trimester prenatal screening in multiple pregnancies. Part II: serum proteins PAPP-A and $\beta$-hCG as markers of adverse pregnancy outcomes. Obstetrics, Gynecology and Reproduction. 2020;14(1):34-43. (In Russ.). https://doi. org/10.17749/2313-7347.2020.14.1.34-43.

13. Obimbo M.M., Zhou Y., McMaster M.T. et al. Placental structure in preterm birth among HIV-positive versus HIV-negative women in Kenya. 
J Acquir Immune Defic Syndr. 2019;80(1):94-102. https://doi. org/10.1097/QAI.0000000000001871.

14. Tusupbekova M.M., Kizatova S.T. Peculiarities of pathomorphology in children with perinatal HIV infection and placental lesions in HIV/AIDS in women. [Osobennosti patomorfologii u detej pri perinatal'noj VICh-infekcii i porazheniya placenty pri VICh/SPIDe u zhenshchin]. Teoreticheskaya i eksperimental'naya medicina. 2017;(4):86-93. (In Russ.).

15. Belotserkovtseva L.D., Kovalenko L.V., Tefnants N.A., Kasparova A.E. Morphofunctional changes in placenta in patients with HIV who transmitted viral infection to their child. [Morfofunkcional'nye izmeneniya v placente u pacientok s VICh pri virusnom porazhenii detej infekciej].
Vestnik Novgorodskogo gosudarstvennogo universiteta. 2018;(6):4-8. (In Russ.).

16. Kolobov A.V. The morphogenesis of the human placenta and its morphofunctional state in the pathology of pregnancy. [Morfogenez placenty cheloveka i ee morfofunkcional'noe sostoyanie pri patologii beremennosti]. Vestnik Sankt-Peterburgskogo universiteta. 2015;11(2):518. (In Russ).

17. Kurbanov Sh.M., Rakhmatulloeva D.M., Yuldasheva O.E., Bagdasarova N.Kh. Peculiarities of fetoplacenta in pregnant women with viral hepatitis. [Osobennosti fetoplacentarnogo kompleksa u beremennyh s virusnymi gepatitami]. Vestnik Avicenny. 2011;(2):44-8. (In Russ).

\section{Сведения об авторах:}

Псеуш Саида Юсуфовна - магистрант биологического фракультета кафедры генетики, микробиологии и биохимии ФГБОУ ВО «Кубанский государственный университет», Краснодар, Россия. E-mail: pseush-saida@mail.ru. ORCID: https://orcid.org/0000-0002-5800-4720.

Зозуля Лада Владимировна - к.б.н., доцент кафедры генетики, микробиологии и биохимии ФГБОУ ВО «Кубанский государственный университет», Краснодар, Россия. ORCID: https://orcid.org/0000-0003-1259-2894.

Михалева Лада Леонидовна - биолог клинико-диагностической лаборатории, Перинатальный центр ГБУЗ «Детская краевая клиническая больница» Министерства здравоохранения Краснодарского края, Краснодар, Россия. ORCID: https://orcid.org/0000-0003-2914-4457.

\section{About the authors:}

Saida Yu. Pseush - Bachelor, Faculty of Biology, Department of Genetics, Microbiology and Biochemistry, Kuban State University, Krasnodar, Russia. E-mail: pseush-saida@mail.ru. ORCID: https://orcid.org/0000-0002-5800-4720.

Lada V. Zozulya - MD, PhD (Biology), Associate Professor, Department of Genetics, Microbiology and Biochemistry, Kuban State University, Krasnodar, Russia. ORCID: https://orcid.org/0000-0003-1259-2894.

Lada L. Mikhaleva - MD, Biologist, Clinical Diagnostic Laboratory, Perinatal Center «Children's Regional Clinical Hospital», Krasnodar, Russia. ORCID: https://orcid. org/0000-0003-2914-4457. 